\title{
Promoting metacognitive reflection: a work proposal
}

\author{
Goulão, Maria de Fátima ${ }^{\mathrm{a}}$; Cerezo Menéndez, Rebeca ${ }^{\mathrm{b}}$ \\ ${ }^{a}$ Universidade Aberta / UIEDF-IE, UL , Portugal; ${ }^{\mathrm{b}}$ Department of Psychology, University \\ of Oviedo, Spain
}

\begin{abstract}
The metacognition as a self-regulatory strategy presents itself as an essential element in the whole process of learning. Lead students to reflect on their way of learning and their strategies, promotes in them this self-awareness and this ability of self-regulation that are very important to help them become "expert learners". It was with this aim that we structured a course prior to the start of students' academic activities, entering for the first time in a degree at university. This work seeks to describe the aims, the structure, and the development of this same course entitled "learn how to learn", as well as with some thoughts on how it took place.
\end{abstract}

Keywords: metacognition, online learning, adults, learning self-regulation 


\section{Introduction}

Students' permanence or failure in online education system is a subject that concerns all those who work in this type of learning system. Woodley and Simpson (2004) say that "most students drop out because of reduced motivation, and that the first thing students do when they are losing motivation is to stop visiting web-sites, watching podcasts, and so on" (page 465). One of the causes of this possible demotivation may be due to the ineffectiveness of strategies used by the students to work the scientific content. Radovan (2011) found in his study a strong relation between motivation, the task value, self-efficacy, and the effort to auto-regulate strategies. Auto-regulation of learning is a primordial factor to an active control of the learning process. The results of Macejka's study (2014) point out that students with a more intern orientation use metacognitive regulation strategies more frequently. These strategies become more sophisticated throughout their learning pace. It is extremely important make students think over their learning strategies, so that they become more autonomous and more expert in their learning process, and thereby ensuring their motivation and consequent retention and academic success.

\section{Work proposal}

In this chapter we are going to present the arguments and the underlying structure to the design of this module.

\subsection{Context}

In the previous chapter, we described the importance of metacognitive knowledge and of self-regulation in the learning process. Since our work was developed within a very specific learning context, we are going to describe some online learning characteristics. This learning system is characterized by the absence of spatial temporal constraints. Thereby, the learning process occurs without being present in the same space and at the same time the different agents (students and professors). The learning environments are organized in a way that students can reach them in any part and at any moment, according to their availability. Within a virtual class, interactions are structured asynchronously in order to allow everyone to participate accordingly to their availability. This system allows to have students from different places of the world, creating real learning and interaction networks. This interaction is done in two ways - between knowledge and between people.

Online learning is a social process which should facilitate collaboration, interaction between people and contents, and implies changes between the different agents in the process - organization, professors, and students. Implies a change in their roles and in the way they relate with themselves, and implies that contents are appropriated. These changes are implemented in the structuring plan and planning courses and curricula, assessment 
systems, ways of teaching and learning, goals to achieve, among others. So we can say that it is expected that students are able to planify their study in order to reconcile to other aspects of their lives; being able to read and write in an adequate way, looking in an effective way into their information sources. It is also expected that they are able to interact with their peers, in virtual class environment, creating their own learning networks. According to Brindley (2004)

Accordingly, studying at a distance requires maturity, a high level of motivation, capacity to multi-task, goal- directedness, and the ability to work independently and cooperatively. (page 287).

In order to ensure that this happens, it is necessary to find ways to help students maintain their motivation and to reactivate the remaining competences. According to different authors, the role played by the structures that support students has become crucial to keep their motivation, their effort and their success (Brindley, 2004; LaPadula, 2003; Mills, 2003; Simpson, 2002).

The professor plans and structures the learning environment in an open and flexible way, with diversified communication resources and channels, with dynamic and motivating teaching materials. This aims to cover a greater number of learners features and learning styles; to guide the student learning in order to develop the ability to learn how to learn (metacognitive reflection), the ability of self-regulation of learning and, with this, the ability of being autonomous as a learner. These characteristics are not only essential for a certain moment as a learner, but also should be part of essential skills in today's society. That is, a lifelong learning society.

Online learning means that the learner becomes a more active element in the whole process, leading to the construction of knowledge. It is expected that students take the initiative to learn and interact with each other. The work of Azevedo \& Cromley (2004) draw attention to the implications of the virtual learning environment design for the acquisition of knowledge. So, "It's the conceiver job to find more appropriate strategies to achieve its goals. The diversity of pathways is vast. Therefore, the online distance education should include a set of learning activities to help the student to achieve the required knowledge, accounting for individual needs and characteristics." (Goulão,2015, page 11) and we add now, that promote students' autonomy.

Together with the characteristics inherent to online education, we cannot fail to equate the features which are related to the students who attend this type of education. As mentioned above, in general, we find an adult audience that seeks to reconcile the different aspects of their family and professional life with the need to increase or consolidate their knowledge and current competencies, and the requirements of studying. The analysis of these situations [Goulão et al, 2015)], aiming to ensure the success of our students, has led us to 
analyze the variables which might help balance how to promote their success. That is, to create support structures, in addition to existing ones, so that students feel more comfortable in learning situations, promoting their empowerment as learners. This is one of the four areas marked by Brindley (2004) that reflect the support for students: "Four major areas for investigation are identified: targeting investment for greatest effect, capacity building, learner support as a professional practice, and fostering student to student support.” (pág.303).

So, one of the variables that was noted, relates to their ability to reflect on their metacognitive strategies and the consequent self-regulated learning.

\subsection{Goals}

Taking into account what was described in the preceding paragraph, this variables' analysis held over two academic years, for students attending undergraduate (bachelor), 1st and 3rd year.

This analysis' results point to the need to work with students in a clear and systematic way, to the issues inherent to their individual features as learners, the need for effective selfregulation of the learning process and how to operationalize all this.

It was in this context that the module learn how to learn arose. This module aims to raise awareness among students of the 1st year degree for the relevance of learning selfregulatory mechanisms. Thereby, the relevance to become more aware of the mechanisms that each one develops to devote themselves to a study / learning task.

In this first exploratory phase, the module will be offered, on a voluntary basis, to students who will start their academic career at Universidade X, in the Education degree. This takes place entirely online, and in specific time periods, according to the students' needs and to the topics' objectives to be addressed.

\subsection{Structure}

To fulfill these goals, the module will be structured in 3-axis and it will primarily supported by the book Comprometer-se com o estudo na universidade: Cartas do Gervásio ao seu umbigo (Rosário, Nuñes \& Pienda, 2006). The authors of this book had the following aims 1) to teach the self-regulated learning processes; 2) to work with students a repertoire of learning strategies that help them in their in college and in their life learning (page 7). Although the students have access to the entire book, it were only worked the following letters on the module development. 


\section{Axis 1}

Goal 1: Planning goals

Material to use: Gervásio’s letters $n^{\circ} 2$ and nº

Letter $\mathrm{n}^{\circ} 2$ - What goals do I have? What is truly a guidance in my acting, in my study at the University, in my hobbies, in my sports, in relations with others, in my laziness ...?

Letter n'6 - Who governs your learning? You know how to distinguish those students who achieve academic success?

\section{Axis 2}

Goal: Planning the task and the time to avoid postpones

Material to use: Gervásio's letter n4

Letter nº - Do you know how to overcome postpones, Gervásio?

\section{Axis 3}

Goal: Preparation for the classroom tests

Material to use: Gervásio’s letters $n^{\circ} 10, n^{\circ} 11$, and $n^{\circ} 12$

Letter $\mathrm{n}^{\circ} 10$ - How do you have this class so well organized? How do you prepare to the exam so intensely?

Letter $\mathrm{n}^{\circ} 11-(. .$.$) must the study be different according to exam type?$

Letter $\mathrm{n}^{\circ} 12$ - So what is this anxiety to the exams?

The choice of just this set of letters held up with different factors. Firstly, we consider that the selected letters address the points considered central to the work that we were developing; secondly, the time we had available, as well as the students, did not allow us to contemplate the 13 letters; lastly, some of the topics covered in the unselected letters were more targeted to a younger audience and with other features, other appeals, and other concerns.

In addition to these thematic areas the module has three other parts. That is, the module learn how to learn is structured around 6 parts. To know:

It starts with a first introduction and, beyond this contextualization, it presents three types of resources - one News Forum, one Doubts and General Questions Forum, and a Module Plan.

These features are accessible throughout the training. The News Forum is only accessed by the teacher in order to provide relevant information about its functioning. 
The Doubts and General Questions Forum allows students to interact between themselves and with the teacher, to clarify possible questions about the module functioning.

In Module Plan we find information on the module's goals, its structure, working methods, resources, skills to achieve, timing, and what is expected of the student throughout their development.

Then is another part where we can find three different items. The first was questionnaire about their willingness to participate in the module; the second was a Presentation Forum; finally, a questionnaire on self-regulated learning strategies.

Next there are the items related to the three axes mentioned above. Each one of these axes is operated independently and this has created a forum for participation of all students. The axis 2, in addition to the forum, students relied on a questionnaire entitled Student Profile, consisting of 20 statements, with answer YES / NO.

Finally, we have an item related to the assessment module made by the students.

Figure 1 schematically seeks to portray the module learn how to learn structure.

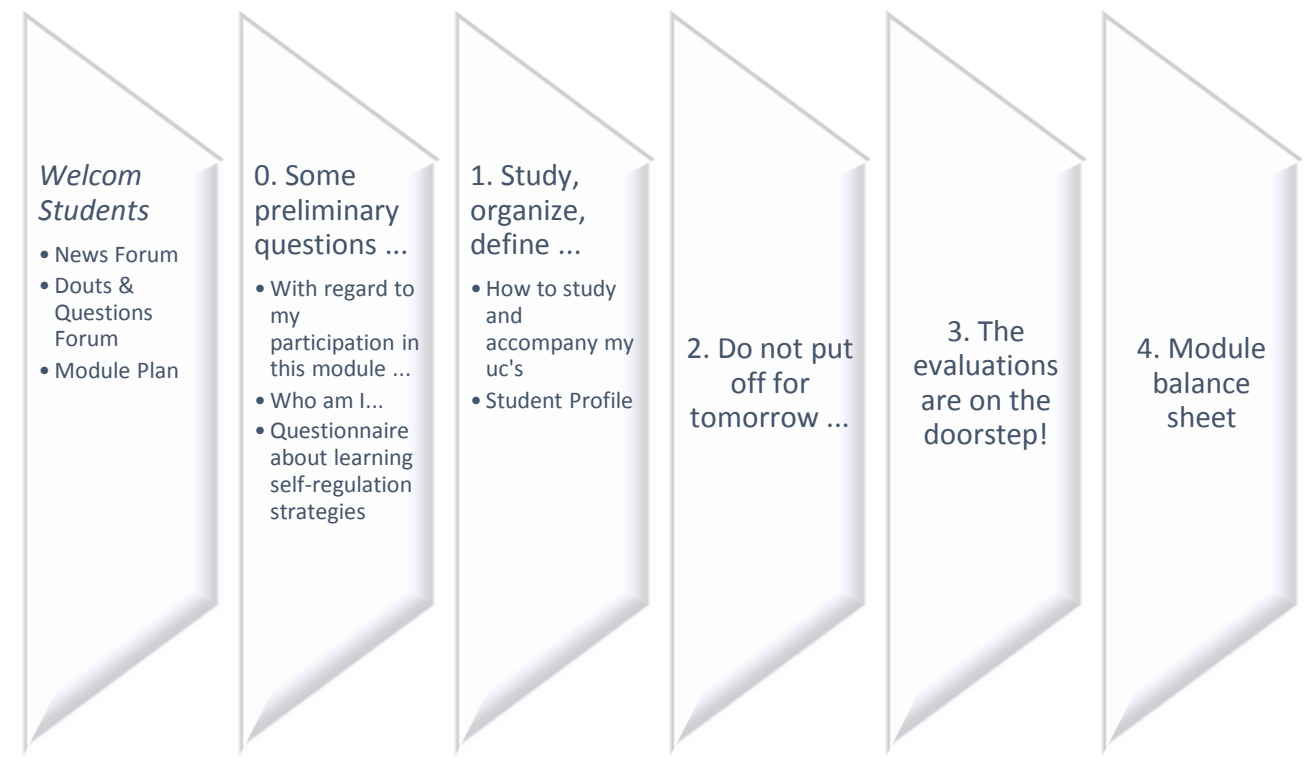

Figure.1. Module learn how to learn structure

\subsection{Development}

These questions are developed in the form of debate, and it is created a forum for each axis where its objectives and the different letters that guide the debate / exchange of ideas 
among students were presented. With this discussion, exchange of ideas and experiences we seek to promote self-reflection on these aspects and, therefore, to develop students competences that make them more self-regulating their learning process. The teacher takes here the role of mediator.

The module was offered completely online.

Given the nature of the contents, the axes 1 and 2 exploration took place early in the school year, immediately before the school activities had started, and the axis 3 the week before the exam period of the 1 st semester.

According to the Module Plan, the item related to the preliminaries questions lasted two days. One welcome message was sent to students in the News Forum calling for the participation in the module. The remaining items would only be made available on the dates indicated for this purpose. After the student's choice, only those who chose to participate continued to have access to the activities of the module. To these students, it was requested to do a brief presentation and at the same time to answer the questionnaire on selfregulation strategies. After this first time, the activities related to the three axes started.

Given the contents nature, we chose to work each of the three axes separately each having a duration of one week. Given the time constraints, the second axis was developed, in part, in the beginning of the school activities.

As we said earlier, the last axis, related to the issues of assessments / exams, took place only after the course of teaching activities and before the week of the classroom exams started (exams or assessment tests continues -efolio).

Each axis began with a teaching message, in the appropriate Forum. This message situated students who were working and made available the respective letter.

\section{Reflection and next perpectives}

As noted earlier, the design of this module had as a precondition to make available to students a structure to support their learning. Not in the sense of formal scientific content, but to help them to reflect, in a systematic and orderly manner, on their own metacognitive strategies of learning and, thereby, provide them with tools for an effective learning selfregulation.

We are in the analysis phase results not of the way that each module took place itself, but also the assessment that the students did with each module. After the analysis of these two parameters, we will seek to adapt it according to the directions outlined and the needs felt throughout the process. So that it becomes an effective response to the needs of our students, and thus help promote the it permanence and it success. 


\section{References}

Azevedo,R. \&Cromley, J.G., (2004). Does training on self-regulated learning facilitate student's learning with hypermedia?.Journal of Educational Psychology, 96(3), 523535

Brindley, J.E. (2004). Learner Support in Online Distance Education: Essential and

Evolving. In Richter-Z.O. \& Anderson,T. (Eds), Online distance education: Towards a Research Agenda (pp.287- 342).Edmonto: AU Press, Athabasca University

Goulão, M.F. (2015). The E-Activities to Support the Process of Teaching and Learning in Online Context, Athens:ATINER'S Conference Paper Series, No:EDU2015-1625.

Goulão,M. F, Seabra,F.,Melaré,D., Henriques,S. and Cardoso,T. (2015). Sucesso, Permanência e Persistência dos Estudantes do Ensino Superior a Distância Online. Revista de Estudios e Investigación en Psicología y Educación, vol. extr.,1,22-26

LaPadula, M. (2003). A comprehensive look at online student support services. American Journal of Distance Education, 17(2), 119-28.

Macejka,M. (2014). The role of grade level and locus of control in self-regulate learning strategies of college students. Journal of Education, Psychology and Social Sciences, 2(1), 1-9

Mills, R. (2003). The centrality of learner support in open and distance learning. In A. Tait, \& R. Mills (Eds.), Rethinking learner support in distance education (pp. 102-13). London, UK: RoutledgeFalmer.

Radovan, M. (2011). The relation between distance students' motivation, their use of learning strategies and academic sucess. Turkish Online Journal of Educational Technology, 10 (1), 216-222

Rosário,P.; Núñez,J. \& Pienda,J. (2006). Cartas do Gervásio ao seu umbigo. Comprometer-se com o estudo na Universidade.Coimbra: Livraria Almedina

Simpson, O. (2002). Supporting students in online, open and distance learning (2nd ed.). London, UK: Kogan Page.

Woodley, A. \& Simpson, O. (2004). Student Dropout: The Elephant in the Room. In In Richter-Z.O. \& Anderson,T. (Eds), Online distance education: Towards a Research Agenda (pp. 459-492).Edmonton:AU Press, Athabasca University 